\title{
Lugares de terra e de água dos Kokama de Nova Aliança, Alto Solimões, Amazonas
}

\author{
Places of earth and water of the Kokama of Nova Aliança, \\ Alto Solimões, Amazonas
}

\author{
Antonia Ivanilce Castro Dácio ${ }^{1}$ \\ Hiroshi Noda ${ }^{2}$
}

DOI: http://dx.doi.org/10.20435/tellus.v18i37.512

\begin{abstract}
Resumo: O estudo teve por objetivo analisar os lugares de uso, conservação e os saberes relacionados às diferentes paisagens e à dinâmica espaço-temporal das espécies cultivadas na Aldeia Kokama Nova Aliança, município de Benjamin Constant, no Amazonas. Foi realizado um estudo de caso tendo como referencial teórico a dialética da complexidade. Nos agroecossistemas em Nova Aliança, ocorre uma associação recursiva com o sistema ambiental, e os saberes transmitidos são reproduzidos e reconstruídos geracionalmente por manifestarem o processo de acoplamento estrutural. Os moradores produzem e reproduzem a diversidade agrícola nos agroecossistemas para viabilizar a manutenção da unidade familiar. As formas de produção adotadas correspondem a sistemas integradores da agricultura aos diversos sistemas acessados. Isto, porque a organização dos agroecossistemas é representada pela conjunção dos ambientes terrestres e aquáticos. Estes agroecossistemas apresentam-se como um conjunto de expressões de conhecimentos e saberes diferenciados, resultantes das espécies cultivadas, do uso, manejo e conservação dos lugares de terra e de água. Por consequência, a experiência comum de vida dos Kokama é resultante, da cultura material e imaterial em sua prática viva nos agroecossistemas.
\end{abstract}

Palavras-chave: estratégias de conservação; saberes; Amazônia.

Abstract: The study aimed to analyze the places of use, conservation and knowledge related to the different landscapes and spatial-temporal dynamics of species cultivated in Kokama's settlement "Nova Aliança", municipality of Benjamin Constant, Amazonas State. The dialectic of complexity was adopted as a theoretical reference of the Case Study. At Nova Aliança's agroecosystems,

\footnotetext{
${ }^{1}$ Instituto de Natureza e Cultura, Universidade Federal do Amazonas (UFAM), Manaus, Amazonas, Brasil.

${ }^{2}$ Instituto Nacional de Pesquisas da Amazônia (INPA), Manaus, Amazonas, Brasil.
} 
a recursive association with the environmental system occurs, and the knowledge is reproduced and rebuild generationally by manifesting the structural coupling process. The settlers produce and reproduce agricultural diversity in the agroecosystems used. This happens because the agroecosystems present themselves as a set of differentiated knowledge and wisdom expressions, resulting of the cultivated species, of their use, handling and preservation of places of earth and water. As consequence, the common life experience of the Kokama is resulted, ad so it is from the material and immaterial culture in the agroecosystem's live practice.

Keywords: conservation strategies; wisdom; Amazon.

\section{INTRODUÇÃO}

O manejo dos agroecossistemas levanta um conjunto de questões relativas à apreensão das especificidades dos sistemas vivos nos processos de conhecimento e de ação humana. O ponto de partida do enfoque reside no reconhecimento da complexidade, da globalidade, da totalidade e da interatividade características dos sistemas vivos e da esfera humana. Assim, a perspectiva sistêmica compreende a ação do homem no ambiente como uma realidade viva, isso significa reconhecer, na complexidade, na globalidade e na interatividade do ambiente e seres humanos, a existência de "sistemas", ou seja, de "conjuntos de elementos em interação formando entre eles uma totalidade" (OLLAGNON, 1997; MORIN, 2015).

O enfoque sistêmico explicita a intervenção e as inter-relações dos seres humanos sobre os agroecossistemas, reflete, por sua vez, sobre as dinâmicas e complexas relações entre as sociedades humanas, as plantas cultivadas e os ambientes, repercutindo sobre as políticas de conservação dos sistemas cultivados, de promoção da segurança alimentar e nutricional das populações humanas, de inclusão social e de sustentabilidade (SANTILLI, 2009).

Em Nova Aliança, são 62 unidades agroecossistêmicas familiares com influência cultural do povo Kokama e peruana, perfazendo o total de 342 moradores no lugar. A partir dos dados de campo de 2016, verificaram-se características de uma população jovem, a faixa etária ( 0 a 16 anos) estava representada por 27,4\% do total de homens e 19,9\% do total de mulheres. A faixa entre 17 a 64 anos representa $25,9 \%$ de homens e $22,8 \%$ de mulheres. A faixa com idade igual ou superior a 65 anos de homens e mulheres de 4,0\%. A faixa etária de 0 a 16 anos 
pode ser considerada como garantia da continuidade da transmissão geracional de saberes em Nova Aliança.

A maioria das famílias faz parte da missão "Ordem Cruzada Católica Apostólica e Evangélica ou Irmandade da Santa Cruz", resultante do movimento messiânico no qual convivem três modalidades de organização social: i) ligada à afirmação da etnia por autoidentificação como organização Kokama na localidade; ii) religiosa; e, iii) associação de produtores.

As organizações locais, segundo Freitas (2002), são resultantes da luta e mobilização pelo acesso à terra, e constituem-se em vetores de articulação e reafirmação da identidade Kokama na Amazônia. Os Kokama, nas últimas décadas, vêm se organizando enquanto povo indígena em torno da luta pelo "resgate de sua cultura milenar" atrelada à demanda por participação nas políticas públicas de cunho étnico (VIEIRA, 2016).

Os moradores de Nova Aliança caracterizam-se por agrupamentos familiares onde a lógica organizacional utiliza os bens comuns. A família apresenta-se como unidade de consumo produção (trabalho) como característica existencial e primeira célula representante da sua organização. O desenho familiar, em sua estrutura produtiva física existente, remete a uma imaterialidade pelo fato de acomodar, em si, o valor do trabalho ao capital do conhecimento, a partir do capital imaterial, ou seja, os agroecossistemas familiares, em conformidade aos preceitos apresentados, estão em acordo com a descrição de Martins (2016), são arranjos com diversificação de cultivos intra e entre espécies e de redes de compartilhamento de recursos genéticos vegetais e saberes associados.

Por meio da aquisição de conhecimento e de ação no manejo e conservação da agrobiodiversidade, os agrupamentos familiares expressam uma grande diversidade de formas sociais de organização da exploração agrícola, identificando agroecossistemas familiares Kokama.

Nos agroecossistemas de Nova Aliança, ocorre uma associação recursiva com o sistema ambiental onde os elementos de fauna, flora, bens comuns como as águas, as terras, as energias, o ar, assim como os saberes transmitidos são reproduzidos e reconstruídos geracionalmente por manifestarem o processo de acoplamento estrutural. Neste, ocorrem associações inter e intraelementos, promovendo transformações nas estruturas e formas do ser e do fazer cotidiano, 
assim como no sistema ambiental, num movimento de circularidade recursiva promotora da conservação autopoiética do viver (MATURANA; VARELLA, 2010), a qual poderá viabilizar processos de sustentabilidade e segurança alimentar.

Esses sistemas complexos, construídos a partir de um arcabouço de experiências e práxis acumuladas, demonstram a dimensão da riqueza dos conhecimentos e saberes Etnoecológicos de onde derivam a organização social, os procedimentos e as técnicas para a produção agrícola (NODA et al., 2010), no sistema ambiental. Para tanto, objetivou-se analisar os lugares de uso, conservação e os saberes relacionados às diferentes paisagens e à dinâmica espaço-temporal das espécies cultivadas na Aldeia Kokama Nova Aliança.

\section{ESTRATÉGIA METODOLÓGICA}

\subsection{A vida nos Beiradões do rio Solimões: a área de estudo}

O interesse da pesquisa foi a área restrita denominada Nova Aliança, localizada no Município de Benjamin Constant na microrregião do Alto Solimões, mesorregião Sudoeste Amazonense em área fronteiriça entre Brasil, Colômbia e Peru. O ambiente em estudo representa a maior bacia hidrográfica em tamanho e quantidade de água, escoando pelos rios Solimões, Japurá e Içá (até São Paulo de Olivença), onde os indicadores do balanço hídrico se apresentam com altos índices de pluviosidade (INSTITUTO BRASILEIRO DE GEOGRAFIA E ESTATÍSTICA [IBGE], s/d).

A área situa-se no sudoeste amazonense na microrregião do Alto Solimões, banhada pelo rio Solimões em seu território brasileiro. A Aldeia Kokama Nova Aliança, de acordo com a autodesignação de seus membros, localiza-se na unidade geomorfológica, denominada terra firme, não inundável, oriunda de formação sedimentar do terciário na margem direita do rio Solimões, nomeada regionalmente de "beiradão" com as seguintes coordenadas geográficas 4²1'00"S e 69³6'27"W. Localiza-se a 46,7 km, em linha reta, do porto da cidade de Benjamin Constant (B.C) (Figura 1), apresentando um tempo de percurso entre o porto de B.C e Nova Aliança de cerca de uma hora, em "voadeira" 3 , motor de popa 90HP.

\footnotetext{
${ }^{3}$ Voadeira - embarcação predominantemente de alumínio ou fibra de vidro, com motor de popa de alta potência (15 a 200 HP). É um transporte rápido de propriedade, em geral, de órgãos públicos e comerciantes locais. É denominado localmente de "deslizador" e/ou "balieira".
} 
Figura 1- Localização geográfica da área de estudo - Aldeia Kokama Nova Aliança. Município de Benjamin Constant, Amazonas, Brasil

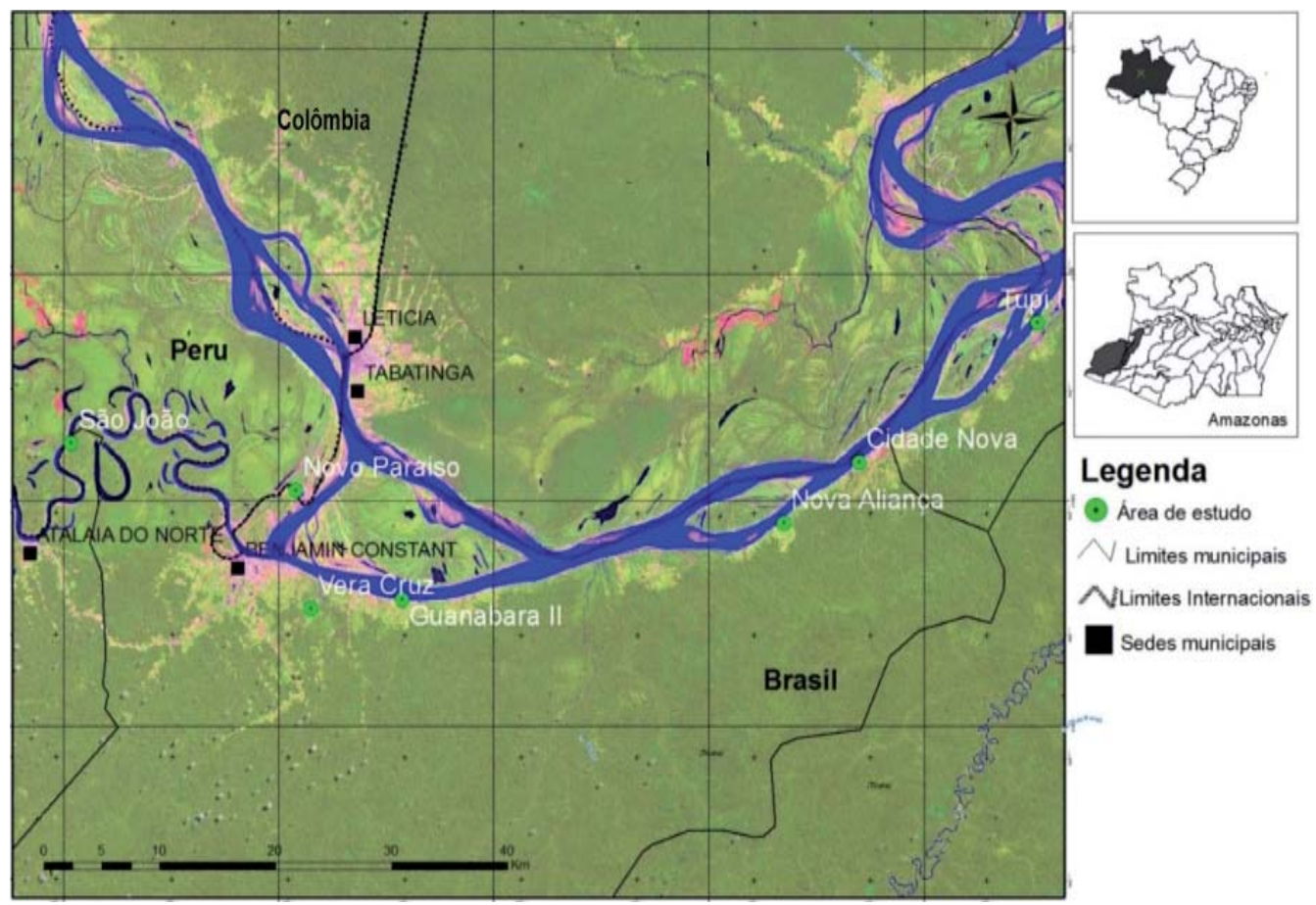

Fonte: Dácio (2017, p. 25).

A microrregião do Alto Solimões é reconhecida pela baixa densidade demográfica, e os municípios mais populosos são Benjamin Constant e Tabatinga, com 39.484 e 61.028 habitantes, respectivamente (IBGE, s/d).

\subsection{Os moradores de Nova Aliança: sujeitos da pesquisa}

A Aldeia Kokama Nova Aliança é formada por 62 unidades agroecossistêmicas familiares perfazendo o total de 342 moradores no lugar com influência cultural do povo Kokama e peruana. Os sujeitos sociais da pesquisa foram 20 unidades familiares entre jovens, mulheres e homens, identificados de acordo com a disponibilidade dos membros das unidades familiares estabelecidas por instrumento de coleta de dados". No entanto ressalta-se o propósito da participação dos sujeitos, isto é, refletir a diversidade dentro de um grupo sob o estudo, em vez de aspirar ao recrutamento de uma "amostragem" representativa (BARBOUR, 2009). 
A autoidentidade dos moradores de Nova Aliança pode ser percebida no exercício cotidiano de trabalho e nas interações socioambientais, num processo de reconstrução cultural da identidade indígena do povo Kokama. No entanto o não reconhecimento pelas instituições formais, por vezes, promovem a negação de sua identidade e de seus saberes, ocasionando redução das conexões nas redes socioambientais. Estes são considerados peruanos por uma abstração, ou seja, uma identidade externa ao grupo, tendo como essência verdadeira sua denominação Kokama, todavia o seu ser em sua totalidade está invisibilizado.

\subsection{ABORDAGEM, DELINEAMENTO METODOLÓGICO E PESQUISA DE CAMPO}

A base lógica da pesquisa foi a abordagem sistêmica enunciada por Morin (2005), visualizando o sistema de maneira paradigmática e complexa ao considerar as relações, interações e organizações entre o todo (agroecossistemas) e as partes (trabalho familiar e segurança alimentar). Todos os fenômenos estão em interação, e o conhecimento é multidimensional, isto é, deve ser percebido a partir de múltiplas dimensões e inter-relações entre o todo e as partes.

Esta pesquisa classifica-se como descritiva e explicativa, conforme apresentado por Gil (1999). Descritiva, por se propor a descrever o conhecimento e o saber dos moradores sobre o uso, manejo e conservação do sistema ambiental. Explicativa, por ser o tipo que mais se aproxima do conhecimento do real na construção das realidades, ou seja, a construção do trabalho é uma aproximação da complexidade real da Aldeia Kokama Nova Aliança.

O controle sobre eventos comportamentais e o focalizar dos acontecimentos contemporâneos ocorreram com a utilização do estudo de caso, fazendo uma análise qualitativa dos dados obtidos (YIN, 2015). O estudo de caso é uma modalidade de pesquisa empírica utilizada para investigar um fenômeno contemporâneo dentro de seu contexto da vida real, especialmente quando os limites entre o fenômeno e o contexto não estão claramente definidos. A lógica que rege o desenho da pesquisa não é a da amostragem, mas sim a da replicação.

$\mathrm{Na}$ busca de responder aos objetivos propostos ligados às categorias de análise, foi realizado: a) O levantamento bibliográfico conduzido em acordo com os pressupostos de Severino (2007); e b) A pesquisa de campo foi conduzida durante os anos de 2014, 2015 e 2016. Foram observados os aspectos sociais, 
processos de trabalho na agricultura, criação animal e extrativismo animal, ligados à vivência social, e foram oportunamente documentadas as práticas produtivas integradas ao cotidiano e a aplicação dos saberes locais, por meio do registro fotográfico e em caderneta de campo. Para Yin (2015) os pontos positivos ressaltados nesta fonte de dados estão associados à capacidade de captar acontecimentos em tempo real, além de tratar diretamente do contexto do evento.

As reuniões com Grupos Focais - utilizam a interação do grupo para a produção de dados e insights. Além de gerarem discussão, revelando significados de determinadas ações, captando também diversidade e diferença, dentro e entre grupos (FLICK, 2004).

Essa técnica foi utilizada em seis momentos e com grupos distintos: 1) Construção do Calendário de atividades agrícolas; 2) Validação dos resultados dos instrumentos utilizados na pesquisa de campo, especialmente o roteiro de entrevistas.

A construção do Calendário Agrícola foi realizada junto às unidades familiares, conforme o seguinte roteiro: O que planta? Onde planta? Quando Planta? Quando produz? Quanto produz? e O que precisa fazer? O resultado do calendário foi um painel com as espécies cultivadas, os cuidados com as plantas, época de plantio, colheita e produção.

Os levantamentos foram realizados em dois casos: 1) Nos sítios, para identificação da diversidade de espécies frutíferas e número de indivíduos. Foi construído um croqui do sítio pertencente à unidade familiar com a delimitação das áreas da "propriedade" por meio de coordenadas geográficas; 2) Nas roças, onde foram identificadas as unidades de paisagem, a idade e o histórico de uso e as espécies e variedades cultivadas. Em ambos os casos, o levantamento foi acompanhado por um membro da unidade familiar.

As entrevistas são constituídas em torno de um corpo de questões do qual o entrevistado parte para uma exploração verticalizada (GRESLLER, 2004). A escolha dessa técnica se deve pelo fato de obter dos entrevistados a compreensão das diferentes estratégias de sobrevivência desses moradores, e foi utilizada para obter dados gerais das unidades familiares. 


\subsection{Procedimentos de análise e éticos}

A análise qualitativa foi realizada por meio de dois procedimentos: 1) A análise enfocada nas verbalizações mêmicas- o discurso dos participantes e suas concepções, conforme Posey (1987), emitidas sobre o sistema de produção; 2) Análise descritiva categorial incidindo na identificação das unidades pertinentes influenciadas por determinado fenômeno "reduzindo os espaços de atributos" de forma a extrair apenas variáveis explicativas pertinentes (GUERRA, 2012). Foi realizada estatística descritiva após alimentação de um banco de dados, em planilha Excel. Posteriormente à sistematização, foram produzidos gráficos e tabelas. O resultado, também, permitiu a demonstração por meio de narrativas e imagens fotográficas.

O projeto foi submetido e autorizado pelo Comitê de Ética em Pesquisa (CEP), conforme Resolução n. 466/2012, com o registro de CAAE n. 43767215.9.0000.5020 e pela Comissão Nacional de Ética em Pesquisa (CONEP), com o Parecer n. 1.472.690. O projeto também foi submetido ao Conselho Nacional de Desenvolvimento Científico e Tecnológico (CNPq) para avaliação do mérito científico da pesquisa e a Fundação Nacional do Índio (FUNAI), para autorização em área indígena. As entrevistas, reuniões e levantamentos foram acordados entre sujeito e pesquisadora.

\section{AGROECOSSISTEMAS FAMILIARES KOKAMA: USO E CONSERVAÇÃO EM NOVA ALIANÇA}

A agricultura é o modo humano de usar os recursos biológicos, físicos e naturais para obtenção de alimentos, remédios, construção, produção de fibras e de gerar renda (BOEF, 2007 p. 37). E, na agricultura familiar, o acesso e a apropriação dos bens, principalmente a terra, compreendida como bens comuns e trabalho, estão ligados à família (LAMARCHE, 1997).

Nas localidades do Alto Rio Solimões, denominadas regionalmente de "comunidades", o emprego da força de trabalho nas unidades familiares ocorre a partir de estratégias de manejo integradas ao processo de conservação dos ambientes acessados nos agroecossistemas, sendo esses sistemas abertos e multidimensionais, aproximando-se da ecofisiologia do sistema ambiental natural (Figura 2). 
Nas áreas de terra firme do ambiente terrestre são cultivadas espécies alimentares de ciclo anual, principalmente a mandioca (Manihot esculenta Crantz) e espécies perenes como as frutíferas lenhosas nativas da Amazônia, como mapati (Pourouma cecropiifolia Mart.), sapota (Quararibea cordata Vischer), abiu (Pouteria caimito (Ruiz \& Pav.) Radlk.), pupunha (Bactris gasipaes Kunth) e outras. As áreas de várzea, constituídas por solos férteis devido à deposição de nutrientes pelo processo de inundação sazonal, são utilizadas para o cultivo de espécies anuais como milho (Zea mays L.), hortaliças e variedades precoces de mandioca.

As formas de produção adotadas correspondem a sistemas integradores da agricultura aos diversos ambientes acessados. A organização dos agroecossistemas é representada pela conjunção dos ambientes terrestres e aquáticos. Nos ambientes terrestres são construídas as moradias, contornadas pelos sítios onde são criados animais de pequeno porte, em geral, aves. As áreas de floresta primária são denominadas localmente como mata na qual são realizadas atividade de extrativismo vegetal e caça, também são transformadas em roças, convertendo-se em capoeiras após repouso. A intersecção entre os ambientes aquáticos e terrestres é utilizada para cultivos de espécies de ciclo curto em áreas denominadas de praias e ilha. 
Figura 2 - Representação esquemática dos agroecossistemas presentes em Nova Aliança, Benjamin Constant, AM

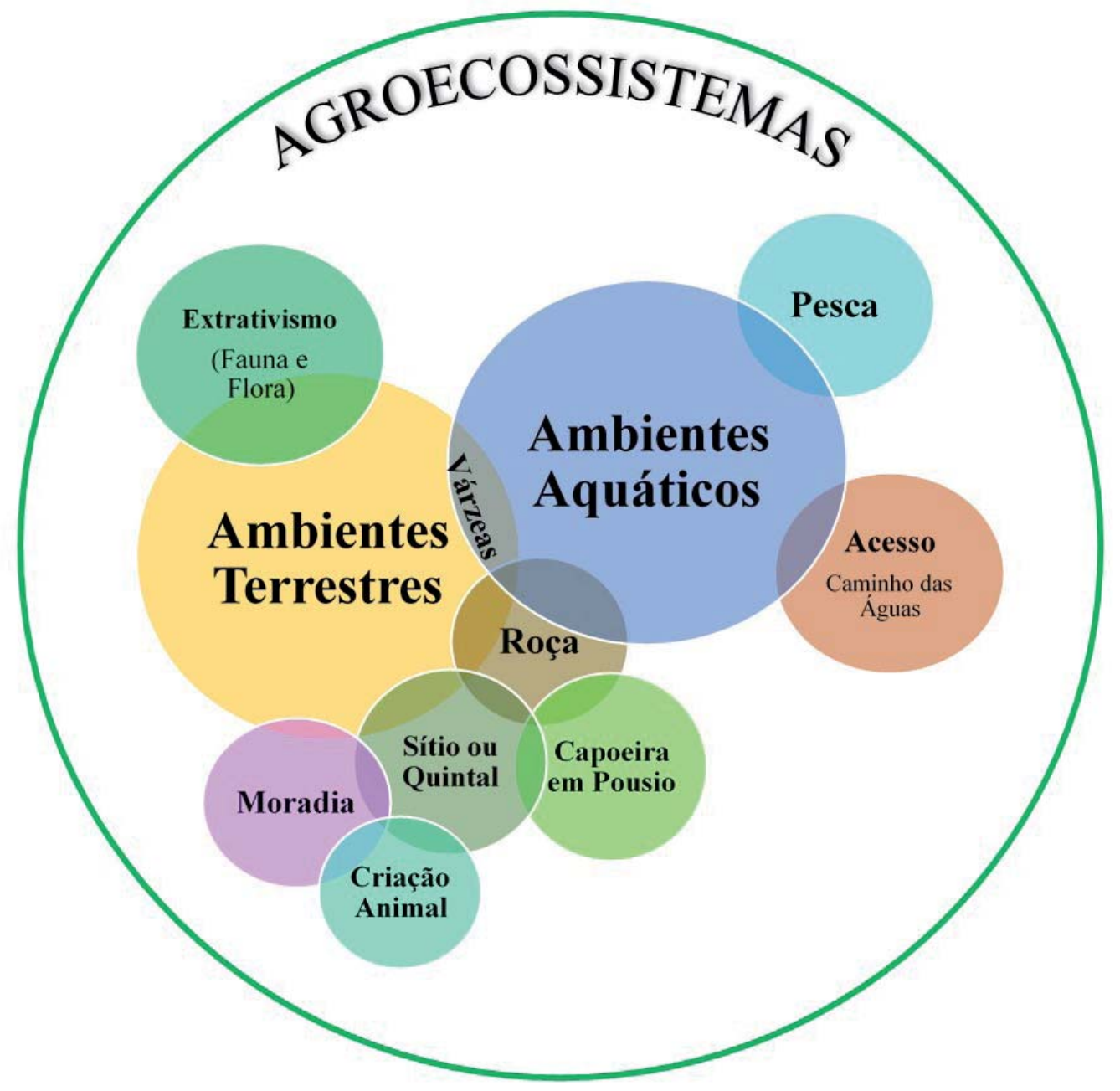

Fonte: Dados de campo, organizados por Antonia I. C. Dácio e Geise de G. Canalez (DÁCIO, 2017).

O espaço residencial, a Capoeira (área de pousio), a Mata, onde ocorre o extrativismo, o Sítio, onde são cultivadas espécies frutíferas perenes, hortaliças, plantas medicinais e criação de animais de pequeno porte, e a Roça, espaço destinado principalmente ao cultivo de banana (Musa sp.) e mandioca (Manihot esculenta Crantz), localizam-se em terra firme. Nas áreas inundáveis (várzea), as Praias são utilizadas para o cultivo de feijão, arroz e hortaliças em geral. As roças 
localizadas em áreas inundáveis são utilizadas para o cultivo de espécies anuais, como o milho, hortaliças e variedades precoces de mandioca.

\subsection{Os lugares de terra: mata, roças, capoeiras e sítios}

As roças são espaços agrícolas abertos e cultivados, principalmente, com as espécies mandioca e macaxeira (Manihot esculenta Crantz) e banana (Musa sp.). Em Nova Aliança, são cultivadas dezenove espécies agrícolas de ciclo anual e curto (Tabela 1). Na reunião com onze unidades familiares, foi citada a presença das espécies de macaxeira e banana, em 10 das 11 roças, e o milho e a mandioca, em oito áreas.

Tabela 1 - Presença de espécies agrícolas, em percentual, nas roças em Nova Aliança, Benjamin Constant, AM. 2015. N=11 (Grupo focal de adultos com 11 unidades familiares)

\begin{tabular}{lc}
\hline Espécies & Presença nas roças (\%) \\
\hline Macaxeira e banana & 90,9 \\
Milho e mandioca & 72,7 \\
Pimentão regional e abacaxi & 45,5 \\
Tomate e feijão & 36,4 \\
Pepino, melancia, coentro e arroz & 27,3 \\
Pimenta ardosa e chicória & 18,2 \\
Pimenta cheirosa, maxixe, mamão, cubiu e cebolinha & 9,1 \\
\hline
\end{tabular}

Fonte: Dados de campo, organizados por Dácio (2017).

Foi identificada uma roça onde eram cultivadas, simultaneamente, três espécies (milho, mandioca e banana), com distintos ciclos de cultivo e arquiteturas, apresentando constituição e formato complexos. Dentro da roça, observou-se a presença de palmeiras adultas que foram protegidas durante o preparo do solo para o cultivo das espécies anuais, cujas folhas são utilizadas para cobertura de residências. A roça representa aquela unidade de paisagem dentro do agroecossistema onde se cultiva, predominantemente, a mandioca.

Nas áreas próximas ou distantes das roças, em processo de cultivo, encontram-se as capoeiras em diferentes estádios de desenvolvimento e as matas com 
fisionomias próximas das florestas primárias. A presença dessas capoeiras é importante para a manutenção da paisagem original por constituírem reservatórios de propágulos para a recomposição florestal, ocorrida por meio de um processo de sucessão de espécies a partir das colonizadoras até às de clímax.

As áreas cultivadas em Nova Aliança estão localizadas, em sua maioria, em terra firme. Contudo as áreas de várzea, denominadas localmente como praias e ilha, são igualmente utilizadas para cultivos de espécies agrícolas de ciclo curto. Essa variação sazonal do nível das águas, conhecido como o pulso das águas, configura quatro períodos distintos, popularmente denominados de "enchente", "cheia", "vazante" e "seca", variando os meses de início e término ao longo da calha, em consequência do complexo mecanismo pluviométrico, conduzido pela descarga do Solimões-Amazonas com seus diversos contribuintes (STERNBERG, 1998 apud MARTINS, 2016, p. 46). Junk (2000, p. 9), por sua vez, denomina como pulso de inundação, geralmente de longa duração e de alta amplitude.

O cultivo das espécies é realizado concomitantemente com a descida das águas, em áreas de terra firme e na várzea. Normalmente, a descida das águas nos municípios de Tabatinga e Benjamin Constant inicia-se na segunda quinzena de maio, deixando o solo descoberto, pronto para começar as atividades agrícolas. Esse elemento foi observado com o plantio de melancia (Citrullus lanatus (Thumb.) Matsum \& Nakai) em maio, bem como, em junho e julho, foram realizados o plantio de cinco e o de oito espécies, respectivamente, em área de várzea.

A agricultura em Nova Aliança está, também, relacionada com a topografia, vindo a requerer o conhecimento acerca do ciclo das águas (pulso das águas - nível da lâmina d'água, frequência e duração das cheias/águas altas) de forma a permitir o uso de técnicas e procedimentos para garantir o sucesso do cultivo, assim como os conhecimentos acerca da fisiologia e ciclo vital das plantas contribuem para a viabilização e êxito dos cultivos nos agroecossistemas.

O tamanho médio das áreas de roça foi de 0,346 hectare, variando de 0,19 ha a 0,49 ha. Em geral, as famílias cultivam em mais de uma área. O número de áreas cultivadas pode ser confirmado no seguinte dístico:

[...] eu tenho três roças, aqui na comunidade cada pai de família tem em média três roças, alguns têm de cinco a seis roças. (Sr. J.T.C., 59 anos). 
Em alguns casos, a unidade familiar cultiva uma única área, contudo constitui uma área representada por diversidade genética intra e interespecífica.

O cultivo em diversas áreas e com espécies distintas é justificado pela preocupação com a oferta regular de produtos destinados ao autoconsumo e à comercialização, conforme discurso:

[...] Eu planto mandioca e macaxeira um pouco antes, depois eu planto banana para aproveitar melhor a minha roça e não faltar produção pra comer e pra vender. (Sr. P.F.M., 36 anos, Nova Aliança, Benjamin Constant, AM, 2015).

Essa preocupação foi observada, igualmente, em outro dístico:

[...] A gente tem que pensar no equilíbrio da produção e venda, quando termina o milho já tem mandioca e banana. (Sr. E.A.M., 42 anos, Nova Aliança, Benjamin Constant, AM, 2015).

Em estudo realizado por Cardoso (2010, p. 25), em quatro comunidades do rio Cuieiras, Amazonas, aponta para as seguintes características das roças: a) pequena extensão de terra; b) uso de tecnologias de baixo impacto; c) área em geral compartilhada com regras de uso e; d) diversidade de espécies e variedades.

A partir dessa premissa, pode-se apontar consonância entre as roças em Nova Aliança e as descritas por Cardoso, conforme a seguir:

a) Quanto a área é em média menor que meio hectare;

b) Sobre o uso de tecnologias de baixo impacto e pelo baixo uso de insumos agrícolas externos, como agrotóxicos e adubos químicos, pode ser ratificado pelo discurso:

[...] Essa roça eu derrubei com o machado. (Sr. L.R.M., 57 anos, Nova Aliança, Benjamin Constant, AM, 2015).

c) A utilização das áreas de cultivos agrícolas é regulada por conciliados verbais e por normas de influência religiosa, ou seja, o desmatamento da floresta primária garante o uso pela unidade familiar promotora da derrubada nos sucessivos cultivos e, posteriormente ao pousio, pode ser utilizada por outras famílias mediante autorização. As áreas de mata primária são consideradas bens comuns;

d) foi constatada a diversidade de espécies e variedades cultivadas, especialmente, de banana e de mandioca. Outra característica do cultivo em áreas de roças, em Nova Aliança, é a reciprocidade, conforme dístico: 
[...] Na hora de roçar a gente faz um ajuri, aqui (referindo-se a área da roça) eu fiz com a ajuda de 10 homens. (Sr. L.R.M., 57 anos, Nova Aliança, Benjamin Constant, AM, 2015).

Os principais problemas ligados aos cultivos de mandioca e banana são a distância entre a roça e o local das moradias, a média de distância de 1,3 km, variando de 0,6 a 2,3 km, dificultando o transporte dos produtos, em particular os destinados para a comercialização, quando é necessário um maior volume de produtos; e ligados à fitossanidade nas bananeiras: broca do tronco (Cosmopolites sordidus), moko (Ralstonia solanacearum), mal do Panamá (Fusarium sp.) e sigatokas negra (Mycosphaerella fijiensis) e amarela (Mycosphaerella musicola). Essas pragas e doenças são conhecidas pelos moradores como "queima na banana". Ainda foram relatados problemas ligados a pragas e doenças nas espécies de ciclo curto.

A importância das casas de farinha rústicas pode ser ratificada pelo número dessas construções, segundo os moradores, são 15 casas. Diferentemente das casas de farinha construídas pela prefeitura do município de Benjamin Constant e pelo Instituto de Desenvolvimento Agropecuário e Florestal Sustentável do Estado do Amazonas (IDAM) que são apenas duas. Outro elemento importante a ser considerado é a otimização da força de trabalho, visto que, em média, a distância das roças para a sede da localidade é de 1,3km. Essas construções são removidas a cada alteração do local da roça e utilizadas para processar pequenas quantidades de farinha de mandioca, em geral, para o autoconsumo. Em um processamento de maior quantidade, destinado à comercialização, é utilizada a 'casa de farinha higiênica'.

Os agroecossistemas inserem-se em um sistema agrícola espaço-temporal cíclico, desde floresta primária (mata), áreas abertas, roças novas e maduras, capoeiras até sítios. As áreas de roças são utilizadas, em média, por dois anos e, posteriormente, são destinadas ao pousio. A área de uso total em Nova Aliança é de cerca de 565 hectares, ou seja, é relativamente baixa, pois, quando dividida pelo número de pessoas da localidade, esse número reduz para 1,6 hectare/ pessoa. O uso do agroecossistema é representado por um mosaico de paisagens com diferentes estágios de sucessão vegetal, apresentando-se como mecanismo de práticas conservacionistas do sistema ambiental. Essas práticas podem ser observadas no seguinte discurso: 
[...] Aqui perto da roça tem essa área que a gente não derruba porque tem madeira de lei, tem da plantada e da mata. Nessa capoeira eu plantei andiroba, cedro e castanha de galinha, plantei uns 100 pés, pra gente usar daqui a uns tempos (Sr. J.C.S., 40 anos, Nova Aliança, Benjamin Constant, AM, 2015).

As capoeiras formam-se como resultado do manejo da paisagem de terra firme em Nova Aliança, sendo, portanto, parte integrante do agroecossistema. Sua principal função é a recuperação da fertilidade do solo, por meio da inserção de espécies, em geral, frutíferas e do tempo de pousio. Foram encontradas, nas capoeiras, espécies frutíferas e para uso em construções, conforme dístico:

[...] Essa área tava com três anos descansando, aqui têm ingá, manga, limão, pupunha, goiaba e paxiúba para assoalhar a casa. (Sr. J.M.M., 39 anos, Nova Aliança, Benjamin Constant, AM, 2015).

A capoeira, também, é utilizada como fornecedora de lenha para uso nas moradias e no processo de fabricação de farinha de mandioca. O tamanho médio das áreas de capoeira é de 1,3 hectare, e o tempo de repouso é de 2 a 5 anos. As capoeiras dão origem a novos sítios quando ocorre o enriquecimento com a introdução de espécies frutíferas; nesse momento, essas áreas saem do circuito do rodízio roça-capoeira-roça.

Outro lugar de terra é o sítio localizado próximo às moradias, destinado ao plantio de espécies frutíferas, hortaliças, medicinais, preparo de mudas, tal como foi observado o cultivo de espécies florestais. Esse espaço representa um importante lugar de conservação de espécies vegetais, representado na imagem, pela diversidade e abundância de fruteiras, sendo, igualmente, realizada a criação de animais de pequeno porte, principalmente aves (galinhas e patos) de forma extensiva, com instalações rústicas destinadas à procriação. Noda et al. (2012) relataram a criação de carneiros nessa localidade, contudo atualmente não foi registrada a presença desses animais. Segundo os moradores, foi inviabilizada pela forma de criação extensiva dos animais, causando prejuízos nos cultivos. O sítio pode estar localizado distante das moradias, quando resulta do enriquecimento das capoeiras em pousio.

Para fins dessa análise, foi realizado um levantamento das espécies frutíferas e do número de indivíduos na fase produtiva, em 12 sítios em Nova Aliança. Nesses locais, foram identificadas 35 espécies de fruteiras. A área média dos 
sítios é de 1732,9 m², variando de 84 a $4637 \mathrm{~m}^{2}$. A idade média é de 21,7 anos, com variação de 9 a 33 anos. A diversidade de espécies e o número de indivíduos não foram influenciados pela idade do sítio. Na análise, cinco sítios S05, S06, S08, S01 e S10 apresentaram as médias de 19,2 espécies e 218 indivíduos por sítio. 0 sítio S10, por sua vez, apresentou o maior número de indivíduos (331), e o sítio S01 maior número de espécies (29); Os sítios S04, S09, S11 têm, em média, 51,3 indivíduos e 13,3 espécies. Os sítios S07, S12 têm, em média, 76 indivíduos e 19 espécies, e os sítios S02 e S03 apresentaram as menores quantidades de indivíduos e espécies, 9 e 6, 6 e 3, respectivamente. Esses sítios também apresentaram os menores tamanhos de área, com a média de $176 \mathrm{~m}^{2}$, essa característica ocorreu pela divisão da área com os filhos, as fruteiras foram suprimidas para ampliação e/ou construção de casas.

Em Nova Aliança, a floresta recebe a denominação local de mata, como já mencionado, e refere-se ao lugar percebido e apropriado por meio das atividades de extrativismo animal e vegetal. Há valoração utilitária da mata, não somente relacionada à coleta de frutas e caça para autoconsumo e, esporadicamente, para a venda, como para a extração de madeira utilizada na construção, geralmente de moradias e de canoas e produtos não madeiráveis, como palhas.

Nessa localidade, a caça é uma atividade realizada na mata e é notadamente masculina, realizada de forma individual ou em dupla. Segundo os moradores, essa atividade foi aprendida com os pais ou avós, demonstrando um caráter geracional. Os locais da captura são: matas primárias, roças e llha do Arariá, e é realizada de forma esporádica com o uso de arma de fogo (espingarda), tanto no período da cheia e da vazante do rio. Entretanto, segundo o relato dos moradores, na época da cheia há maior disponibilidade de animais em relação à seca, devido a abundância de alimentos para os animais, outra característica da captura na ilha, no período das águas altas, é a menor quantidade de área disponível para os animais, esse elemento é considerado facilitador da captura. O resultado da jornada da caça, além de contribuir na alimentação e propiciar a variação do cardápio, destina-se também ao compartilhamento com parentes e/ou membros da localidade e, em menor escala, à venda. Em Nova Aliança, seis moradores são reconhecidos pela comunidade como detentores da práxis da captura de animais, esses moradores realizam essa atividade, em média, há 37 anos. 
As estratégias de uso espacial e temporal dos agroecossistemas, mata primária, roças, capoeiras em pousio, em Nova Aliança, são complexas e visam à maximização do uso da diversidade biológica e dos processos ecológicos por meio da multiplicidade de práticas e saberes de uso e conservação. Essas estratégias são fundamentadas na: a) "imitação" da sucessão florestal por meio do ciclo agrícola; b) manutenção simultânea de um conjunto de roças com época de maturação distintas; c) aplicação de práticas agrícolas integradas, geradoras e amplificadoras da diversidade. Essas características já foram observadas por Toledo (2005) e corroboradas por Martins (2016, p. 58), assim, a manutenção das capoeiras representa, aqui, uma outra estratégia de recursividade e complementaridade, permitindo ao agricultor o uso dos serviços ambientais na conservação e melhoria do solo das áreas agricultáveis.

\subsection{As estratégias de conservação dos recursos genéticos vegetais}

Das 19 espécies cultivadas nas roças em Nova Aliança, a banana (Musa sp.) apresentou a maior diversidade intraespecífica, com 11 variedades, sendo: pacovã, maçã, prata e peruana as mais frequentes, presentes em 16, 11, 11, 10 e 8 roças das dezoito roças estudadas. Nas demais variedades de banana, a presença foi inferior a 50\% nas roças. Já a mandioca (Manihot esculenta Crantz) apresentou cinco variedades (Tabela 2), tendo a mandioca racha terra presente em $100 \%$ das roças, e as demais estiveram presentes em uma ou duas roças.

Tabela 2- Espécies e variedades locais cultivadas nas roças em Nova Aliança. Benjamin Constant, AM, 2015. $\mathrm{N}=18$ roças de banana; 6 roças de mandioca. Ano agrícola 2015

Espécies Variedades citadas (denominação local) $\begin{aligned} & \text { Número de } \\ & \text { variedades }\end{aligned}$

\begin{tabular}{lll}
\hline Banana & Pacovã, maçã, prata, peruana, inajá, compri- & 11 \\
(Musa sp.) & da, capirona, fhia 18, seda, sapo, dois cachos. & \\
Mandioca & Calaí, pagoão, racha terra, samaúma e varuda & 05 \\
\hline
\end{tabular}

Fonte: Dados de campo, organizados por Dácio (2017). 
A mandioca (Manihot esculenta) é uma espécie de reprodução sexuada alógama, cultivada por meio da propagação vegetativa. Em Nova Aliança, as variedades de mandioca: calaí, pagoão, racha terra, samaúma e varuda são plantadas utilizando os toletes, denominado pelos habitantes locais, como maniva. Outro elemento favorecedor da diversidade intraespecífica é a incorporação à coleção de variedades de mandioca, obtidas por meio da reprodução "natural" de sementes. Essa mandioca de ocorrência espontânea é percebida como diferente da "plantada", as características mais nítidas para os moradores são: tipos de raiz "a raiz cresce pro fundo" (Sr. A.A.A., 60 anos), ou seja, a raiz é pivotante, e o caule é único.

Diversos autores já descreveram a importância da 'mandioca de sementes' para a diversificação da espécie, tendo em vista a produção de mandioca ocorrer, há muitos anos, por meio da propagação vegetativa. Entretanto a mandioca não perdeu a capacidade de reproduzir-se de forma sexuada (MARTINS, 2005; EMPERAIRE; PINTON; SECOND, 1998; CHERNELLA, 1997). Em trabalhos realizados nos rios Cuieiras e Solimões, também foi registrada a presença das plantas de mandioca originadas de sementes, denominadas localmente, no rio Solimões, por "mandioca nascida" (MARTINS, 2016; CARDOSO, 2010).

Nessa perspectiva, a manutenção de variedades oriundas de sementes favorece a conservação da agrobiodiversidade e, como relata Emperaire (2008), está ligada tanto a regras sociais de trocas de variedades como a práticas agrícolas. Em Nova Aliança, a incorporação de novas variedades comporta-se de acordo com a descrição de Cardoso (2010, p. 138), é uma estratégia para renovar o estoque e atua como forma de manutenção da heterogeneidade.

Outra estratégia presente em Nova Aliança é a autonomia em relação à obtenção de sementes. A origem das sementes é da própria unidade produtiva ou obtida por meio das relações de reciprocidade na localidade e na vizinhança, exceto as espécies de ciclo curto: coentro e melancia; assim, das 19 espécies cultivadas nas roças, 17 delas são próprias. Em geral, as sementes guardadas são selecionadas por um criterioso processo, no qual os moradores selecionam, conforme os dísticos, para a seleção das bananeiras:

[...] tira os filhos sem doença; escolhe as plantas grande e mais bonitas, as que dão mais cachos. (Sra. E.M.M., 45 anos); para seleção de mandioca e macaxeira: escolhe as plantas maior e mais bonita; as que dá mais batata 
e mais rápido e as que não morre. (Sra. E.M.M., 45 anos, Nova Aliança, Benjamin Constant, AM, 2015);

[...] se cozinha bem, se dá para vender; se a mandioca é mais rápida pra fazer a farinha. (Sr. P.F.M., 36 anos; Sra. E.M.M., 45 anos, Nova Aliança, Benjamin Constant, AM, 2015).

Para outras espécies:

[...] faço a escolha do fruto mais bonito e grande para tirar a semente. (Sr. E.T., 66 anos, Nova Aliança, Benjamin Constant, AM, 2015)

[...] por exemplo no pimentão a fruta é a maior, a gente apanha bem madura; Já para a cebolinha plantamos as batatinhas para alimentar e dá mais filhotes nos canteiros, as mudas plantamos no terreno de casa ou em capoeira para aumentar a quantidade. (Sr. E.A.M., 42 anos, Nova Aliança, Benjamin Constant, AM, 2015).

A seleção de sementes e mudas, em geral, está ligada à sanidade da planta, ao tamanho do fruto ou à maior quantidade da produção, à precocidade, ao tempo de cozimento e à aceitação do mercado, no caso da macaxeira.

Em Nova Aliança, a seleção das sementes e mudas ocorre dentro das áreas cultivadas, ou seja, não há uma roça específica para obtenção de mudas e sementes. Há uma preocupação em coletar, selecionar e armazenar as sementes e mudas para os próximos cultivos. A manutenção das variedades locais está ligada, principalmente, à não dependência do mercado, implicando uma relativa economia para a unidade familiar e seleção cuidadosa das características das espécies desejadas para perpetuação.

Para Altieri (1999), a diversidade inter e intraespecífica promove uma dieta mais diversificada, a estabilidade da produção, a minimização de riscos, a redução da incidência de insetos e doenças, o uso eficiente da mão de obra familiar, o aumento da produção com recursos limitados e a maximização dos retornos sob baixos níveis de tecnologia. Cleveland, Soleri e Smith (1994) e Martins (2005) referem-se às variedades locais, mantidas pelos agricultores, como um componente-chave dos seus sistemas agrícolas, funcionando como matéria-prima para o desenvolvimento das variedades modernas e demonstrando a importância estratégica como mecanismo de conservação da agrobiodiversidade. 


\subsection{Os lugares de água da pesca e os caminhos}

Os ambientes aquáticos, lugares das águas, são reconhecidos como espaços sociais e conservados pelas unidades familiares como bens comuns, reconhecidos por jovens e adultos de Nova Aliança. Tais locais foram citados como componentes dos ambientes aquáticos, na totalidade de 11, conforme a seguir: rio, beira do rio, lago, paraná, igarapé, furo, igapó, enseada, restinga, praia e ressaca (Figura 3).

A Figura 3 representa a práxis para realizar as atividades de pesca de jovens e adultos nos diferentes componentes aquáticos. Os locais utilizados com maior frequência são o rio, com 35,7\% e 32,3\% por jovens e adultos, respectivamente, neste caso, para fins de análise, foi somada a média do uso da beira do rio. O uso dos componentes para a pesca é seguido pela pesca realizada nos lagos, com $23 \%$ por jovens e $22,3 \%$ por adultos. Os demais locais representam taxas igual ou inferior a $10 \%$. Pode-se observar as taxas similares de uso do ambiente aquático por jovens e adultos, isso corresponde à eficiência da transmissão geracional, representada pela práxis cotidiana do saber-fazer no sistema ambiental.

Figura 3- Componentes do Ambiente aquático utilizados para a pesca de jovens e adultos em Nova Aliança. Benjamin Constant, AM, 2016. $\mathrm{N}$ = dois grupos focais de jovens e adultos (20 participantes)

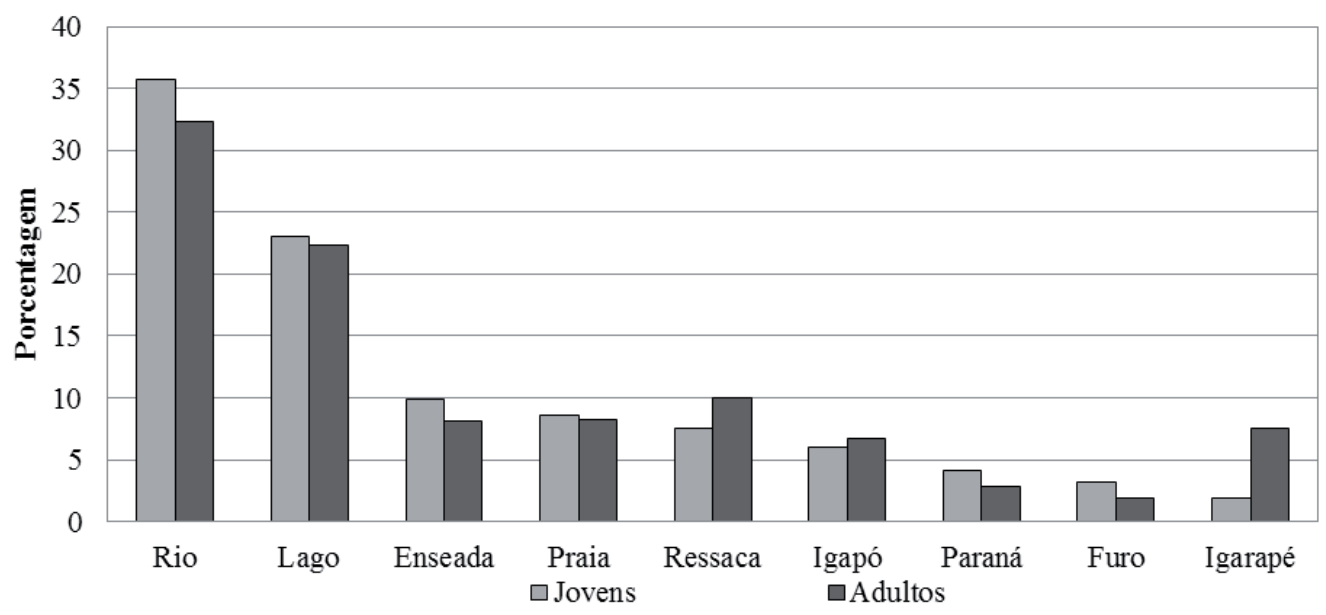

Fonte: Dados de campo, organizados por Dácio (2017). 
As descrições do ambiente aquático correspondem às seguintes características: coloração da água; sazonalidade e transformações locais; tipo de vegetação, diversidade e tamanho das espécies vegetais; identificação de espécies da fauna, comportamento e reprodução; identificação de espécies peixes (diversidade e abundância), melhores locais e épocas de captura e apetrecho utilizado; tipo de solo e topografia com orientação para o cultivo de espécies agrícolas. Os locais são valorados pela produção e reprodução da vida doméstica, como lugar de fornecimento de alimento e como 'estradas', vias de acesso, conduzindo-os em movimento de ir e vir (Tabela 3).

Tabela 3 - Nomenclatura e conceituação social dos ambientes aquáticos descritos por adultos e jovens de Nova Aliança, Benjamin Constant, 2015. N = dois grupos focais de jovens e adultos (20 participantes)

\section{Nomenclatura}

O rio, a água é branca, tem barranco, tem mato, o rio é grande não troca de cor, de um lado tem terra e do outro alaga; tem capim navalha, cheio de correntezas, com muito banzeiro quando chove forte, quando

Rio tá enchendo corre muito pau e capim de toda qualidade; tem peixe grande e de couro, e pequeno, cobra, boto e jacaré; tem peixe grande no inverno e mais no verão; o rio é tudo, é água que a gente precisa, é peixe que a gente come, é caminho, por onde a gente vai e volta.

A água é branca, é onde se encosta o rio; é um lugar bonito; tem muitos bichos, tem porco do mato, praia, tem lugar pra plantar; também tem peixes e cardumes, barranco, paus dentro d'água, tem mata pequena e alta de vários tipos, tem árvore caída, tem capim; cai muito barranco; os pescadores pescam com espinhel; pesca de malhadeira, tarrafa, linha comprida e espinhel; a gente também pesca e coloca malhadeira; tem balsas pequenas de lavar; lava roupa e encosta a canoa; tem barranco; é da própria natureza; tem corredeira, rebojos e, passagem de bauceiros.

O lago é bonito, redondo, outros são compridos; o lago fica no outro lado da comunidade, fica distante do rio é dentro da ilha, é um espaço livre com muito peixe e é fácil de pegar, tem cobra, jacaré e a água é preta e branca dependendo do tempo; na cheia a água fica branca e no verão a água fica preta; terra baixa, tem mureru, capim muri, vitória régia, aninga; as árvores quando enchem fica no fundo, têm pássaros; 


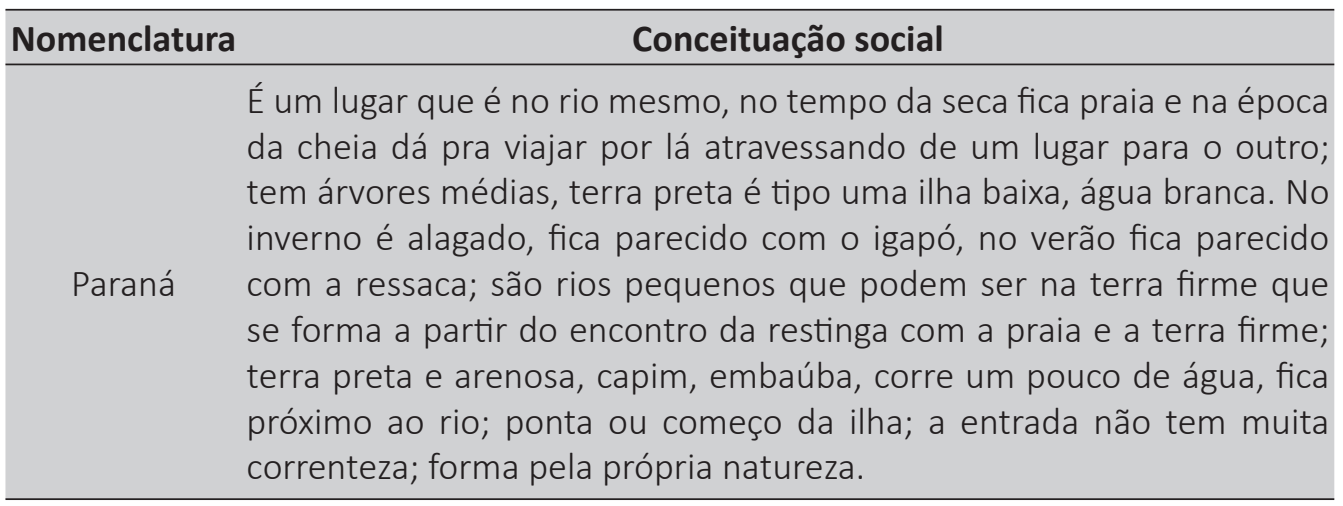

É pequeno, água de cor cristalina e fria. É também rodeada de árvores pequenas e grandes, tem peixe e cobra; tem na terra firme que desemboca na beira do rio, no verão fica só um poço e no inverno fica Igarapé cheio, tem pedra e peixe pequeno; lugar que é comprido, cheio de curva; uns rasos, outro são fundo; corre pouco, tem árvores ao redor e às vezes tem casa ao redor; é um cano de água limpa; as árvores tem cipós, é fonte para os animais da mata banhar e matar a sede. Já o igarapé de terra de várzea vai pro lago.

É um lugar onde dá para atravessar no rio para ir para outros lugares, é
estreito; é tipo um igarapé que liga de um lugar para outro; é um atalho
pra adiantar o percurso da viagem; tem mais no inverno; água barrenta
e às vezes preta; é por onde as canoas que atravessam as voltas do rio;
é um atalho para evitar dar a volta no rio, chega mais rápido; cheias
de paus e com correnteza; tem muito peixe e muita árvore; mas pega
pouco peixe; tem uns longe que são perigosos porque sempre assaltam.
É uma ilha que quando enche o rio, fica alagado só no inverno, as
árvores ficam tudo dentro da água; é quando alaga a mata se cobre
com a água que é preta, tem um monte de folha no fundo, galho; fica
no lago; quando enche tem munguba, onde os peixes vão comer suas
frutinhas; no tempo da seca os peixes de maior porte morrem; pega
peixes de malhadeira e caniço, tem sardinha, branquinha, tem também,
pirarucu e jaú grande.
Igapó barranco, fica na beira do rio, onde fica caindo a terra; tem muito
pau caindo; corre menos capim; a água tem é branca e rodeada de
árvore; tem cobra, tem muito peixe grande, lá se pesca de anzol grande
porque os peixes são grandes, pesca mais à noite; um lugar de pesca; a
própria natureza é que faz isso.




Nomenclatura
Tem a terra baixa; serve para fazer roça, tem casa ao redor, tem fruta
e madeira, tem árvore alta; a água muda de cor, no repiquete é preta
e na cheia fica branca, a água preta é igual à do lago; é um pedaço de
terra que sobra na época da cheia custa alagar, existe restinga alta e
restinga baixa, a restinga é mais alta do que a praia; a diferença é que a
baixa alaga rápido; tem bastante peixe, tem muita curimatã, cará açu e
tucunaré, árvores altas; às vezes acha caça, jabuti.
É um lugar que sai bastante no verão, no verão aparece e no inverno
desaparece; todo ano enche e seca e às vezes anda; é olugar mais bonito,
tem gaivotas; é um lugar de terra que está ligado com a restinga baixa;
tem areia que serve pra plantar, na areia que é bom para plantar feijão;
água baixa e tem capim, ficam com uns laguinhos, pau seco, mato baixo;
dá muito peixe na beira da praia, pegamos todo tipo de peixe, arenga,
tracajá; tem areia branca e preta, pau seco; água é parada e corre um
pouco; é da própria natureza, serve para a criação de tartaruga e tracajá.
A água é parada, tem a cor branca, tem paus dentro da água, tem um
lado que é barranco e o outro é praia, é um lugar perto da praia que
é baixa e parada, a ressaca é quando nasce a praia emendando com
a ilha; lá se forma uma área que tem a entrada parecida com o lago
e dá peixe; tem capim espinho, embaúba, muita lama; as árvores são
pequenas; é bom pra pescar com poita, espinhel e malhadeira, tem
muito peixe, tem muito bodó.

Fonte: Dados de campo, organizados por Dácio (2017).

Diversos autores já mencionaram a complexidade do conhecimento dos povos na Amazônia, entre eles Begossi e Silva (2006), Silvano e Begossi (2005) e Silvano et al. (2008). Os saberes complexos dos moradores de Nova Aliança sobre os ambientes aquáticos podem ser ratificados, conforme a seguir: A complexidade é resultante de um paradoxo próprio da relação ecológica, e, nessa dependência tecida e constituída, há a autonomia dos seres. O desenvolvimento do conhecimento exige a observação de si mesmo observando os sistemas, num movimento dialético para conhecer o seu conhecimento. Assim, um sistema não pode ser descrito e explicado no nível das partes, mesmo quando sua concepção for isolada e ligadas apenas por ações e reações (MORIN, 2013). A decomposição analítica em elementos decompõe, também, o sistema, cujas regras são transformadoras e não aditivas (MATURANA; VARELA, 2010; MORIN, 2013). 
Os componentes do ambiente aquático foram descritos com beleza estética: "um lugar bonito", podendo ser comparados à obra de arte. Esse entendimento fundamenta-se em Bourdieu (2009) e Morin (2013), quando mencionam a existência de uma obra de arte como detentora de códigos de decifração, constituídos historicamente e reconhecidos como a condição de apropriação simbólica. A obra de arte, nesse caso, não é materializada, ela é imaterial, fruto de processos cognitivos dos moradores de Nova Aliança e das inter-relações com o sistema ambiental em movimentos recursivos, permitindo análises plásticas da luz, das cores e da composição. Essa obra de arte manifesta-se como Morin (2013) descreve: "eles produzem ser e existência a partir de materiais brutos. A geração de um ser poder ser por outro ser é a forma biológica final da poesia".

\subsection{Saberes e temporalidades nos agroecossistemas}

O saber é, antes de tudo, uma capacidade prática, uma competência que não implica necessariamente conhecimentos formalizáveis, codificáveis. Eles não são ensinados; aprendem-se pela prática, pelo costume, isto é, pelo exercício das práxis (GORZ, 2005, p. 32). Para o mesmo autor, os saberes comuns ativados pelo trabalho imaterial não existem senão em sua prática viva e por ela, resultantes da experiência comum da vida em sociedade (GORZ, 2005, p. 33), ou seja, um processo histórico de acumulação e transmissão de conhecimentos empíricos e experienciais. Ainda se ressalta que, para Maturana e Varela (2010 p. 36), todo fazer é um conhecer e todo conhecer é um fazer.

A práxis de trabalho nos agroecossistemas é um conjunto de expressões de saberes diferenciados resultante do uso, manejo e conservação dos lugares, espécies cultivadas e da cultura material e imaterial. Trata-se de "uma diversidade de processos envolvendo diversas escalas ecológicas, biológicas, socioculturais e temporais, atravessadas pelos domínios da vida material, social e econômica, com funções simbólicas e produtivas" (EMPERAIRE, 2010, p. 9).

Os moradores de Nova Aliança referem-se aos agroecossistemas com sentimentos de pertença, recordações das histórias dos antepassados, os quais Ihe dão significados existenciais, isto é, um sentimento profundo pelo lugar, acrescido pelas contínuas experiências ao longo dos anos (TUAN, 2013, p. 47). Para Santos (2006), tempo, espaço e lugar estão associados a técnicas e objetos produzidos em cada 
momento histórico, sendo indicativos das transformações sociais e dos modos de produção. O lugar traz consigo a imaterialidade sob a forma de sentimento e, quando vinculado à paisagem, é responsável por estabelecer elos significativos arraigados na própria construção do indivíduo (TUAN, 2013).

Os saberes em Nova Aliança são, igualmente, traduzidos pela descrição de Gorz (2005, p. 09) como o saber da experiência, o discernimento, a capacidade de coordenação, de auto-organização e de comunicação, quer dizer, um saber vivo adquirido do trânsito vivificado, pertencente à cultura do cotidiano. Os moradores de Nova Aliança vivificam o todo nas partes e as partes no todo, demonstrando tanto a complexidade das práxis sobre o sistema ambiental, como a transdisciplinaridade. Esse saber vivo é, também, recursivo e responsável pela transmissão geracional, conforme aponta Maturana (2014): "todo viver se faz no conhecer e todo conhecer se faz no viver". Desse modo, a realidade construída não explica, na sua totalidade, o real vivificado no cotidiano pelos moradores de Nova Aliança.

\section{CONCLUSÕES}

As formas de produção adotadas correspondem a sistemas integradores da agricultura aos diversos ecossistemas acessados. Isto porque, a organização dos agroecossistemas é representada pela conjunção dos ambientes terrestres e aquáticos e apresentam-se como um conjunto de expressões de conhecimentos e saberes diferenciados resultantes do uso, manejo e conservação dos lugares, das espécies cultivadas e da cultura material e imaterial em sua prática viva, e por ela, resultantes da experiência comum de vida do povo Kokama.

\section{REFERÊNCIAS}

ALTIERI, M. Agroecologia: as bases científicas da agricultura alternativa. Tradução Patrícia Vaz. Rio de Janeiro: PTA/FASE, 1999. 240p.

BARBOUR, R. Grupos focais. Tradução Marcelo Figueiredo Duarte; consultoria, supervisão e revisão técnica desta edição Leandro Miletto Tonetto. Porto Alegre: Artmed, 2009. 216p.

BEGOSSI, A.; DA SILVA, A. L. Ecologia de pescadores da Mata Atlântica e da Amazônia. São Paulo: Hucitec, 2006. 
BOEF, W. S. Biodiversidade e agrobiodiversidade. In: BOEF, W. S.; THIJSSEN, M. H.; OGLIARI, J. B.; STHAPIT, B. R. (Org.). Biodiversidade e agricultores: fortalecendo o manejo comunitário. Porto Alegre: L\&PM, 2007. p. 36-40.

BOURDIEU, P. Economia das trocas simbólicas. São Paulo: Perspectiva, 2009.

CARDOSO, T. M. O saber biodiverso- práticas e conhecimentos na agricultura indígena do baixo Rio Negro. Manaus: Editora da Universidade do Amazonas (EDUA), 2010. 190p.

CHERNELLA, J. Yanomami warfare: a political history- Ferguson, R. B. American Ethnologist, n. 24, p. 227-9, 1997.

CLEVELAND, D. A.; SOLERI, D.; SMITH, E. S. Do folk crop varieties have a role in sustainable agriculture? BioScience, v. 44, n. 11, p. 740-51, dez. 1994.

DÁCIO, A. I. C. Segurança alimentar e conservação nos agroecossistemas no Alto Solimões, Amazonas. 2017. 161p. Tese (Doutorado em Ciências do Ambiente)- Universidade Federal do Amazonas (UFAM), Manaus, 2017.

EMPERAIRE, L. (Org.). Dossiê de registro: o Sistema Agrícola Tradicional do Rio Negro. Brasília: ACIMRN/IPHAN/IRD/Unicamp-CNPq, 2010. 235p. Disponível em: <http://portal. iphan.gov.br/uploads/ckfinder/arquivos/Dossie_de_registro-O_Sistema_Agricola_ Tradicional_do_Rio_Negro.pdf>. Acesso em: 11 dez. 2016.

EMPERAIRE, L. Mandioca, raiz do Brasil. In: RICARDO, B.; CAMPANILI, M. (Ed.). Almanaque Brasil Socioambiental. São Paulo: Instituto Socioambiental, 2008. p. 420-1.

EMPERAIRE, L.; PINTON, F.; SECOND, G. Gestion dynamique de la diversité variétale du manioc en Amazonie du Nord-Ouest. Natures Sciences Sociétés, v. 6, n. 2, p. 27-42, abr./ jun. 1998.

FLICK, U. Uma introdução à pesquisa qualitativa. 2. ed. Tradução Sandra Netz. Porto Alegre: Bookman, 2004. 312p.

FREITAS, M. A. B de. O povo Kokáma: um caso de reafirmação de identidade étnica. Manaus: Universidade Federal do Amazonas, 2002. 106p.

GIL, A. C. Métodos e técnicas de pesquisa social. 5. ed. São Paulo: Atlas, 1999. 206p.

GORZ, A. O imaterial: conhecimento, valor e capital. Tradução Celso Azzan Júnior. São Paulo: Annablume, 2005.107p.

GRESSLER, L. A. Introdução à pesquisa: projetos e relatórios. 2. ed. São Paulo: Loyola, 2004. 300p.

GUERRA, I. C. Pesquisa qualitativa e análise de conteúdo: sentidos e formas de uso. Parede, Portugal: Principia, 2012. 95p. 
INSTITUTO BRASILEIRO DE GEOGRAFIA E ESTATÍ́SITICA (IBGE). Cidades@. Diretoria de Pesquisas- DPE- Coordenação de População e Indicadores Sociais- COPIS. Disponível em: <http://cidades.ibge.gov.br/xtras/perfil.php?codmun=130060>. Acesso em: 7 jan. 2016.

JUNK, W. J. Neotropical floodplains: a continental-wide view. In: JUNK, W. J.; OHLY, J. J.; PIEDADE, M. T. F.; SOARES, M. G. M. (Ed.). The Central Amazon floodplain: actual use and options for sustainable management. Leiden, Netherlands: Backhuys Publishers, 2000. p. 5-26.

LAMARCHE, H. A agricultura familiar. São Paulo: UNICAMP, 1997. v. 1.

MARTINS, A. L. U. Conservação da agrobiodiversidade: saberes e estratégias da agricultura familiar na Amazônia. 2016. 213p. Tese (Doutorado em Ciências do Ambiente) - Universidade Federal do Amazonas (UFAM), Manaus, 2016.

MARTINS, P. S. Dinâmica evolutiva em roças de caboclos amazônicos. Estudos Avançados, São Paulo, v. 19, n. 53, p. 209-20, jan./abr. 2005.

MATURANA, H. R. A ontologia da realidade. 2. ed. Belo Horizonte: Editora UFMG, 2014. 414p.

MATURANA, H. R.; VARELA, F. J. A árvore do conhecimento: as bases biológicas da compreensão humana. 8. ed. São Paulo: Palas Athena, 2010.

MORIN, E. O método 2. A vida da vida. Tradução Marina Lobo, Simone Ceré e Tânica do Valle Tschiedel. 5. ed. Porto Alegre, RS: Sulina, 2015. 527p.

- O método 1. A natureza da natureza. Tradução Ilana Heineiberg. 3. ed. Porto Alegre: Sulina, 2013. 479p.

Ciência com consciência. 7. ed. Rio de Janeiro: Bertrand Brasil, 2005. 350p.

NODA, S. do N.; MARTINS, A. L. U.; NODA, H.; SILVA, A. I. C. da; BRAGA, M. D. S. Paisagens e etnoconhecimentos na agricultura Ticuna e Cocama no Alto Rio Solimões, Amazonas. Boletim do Museu Paraense Emílio Goeldi. Ciências Humanas, Belém, PA, v. 7, n. 2, p. 397-416, maio/ago. 2012.

NODA, S. do N.; NODA, H.; MARTINS, A. L. U.; MARTINS, L. H. P.; SILVA, A. I. C. da; DÁCIO, D. da S.; MENDONÇA, M. S. P.; BRAGA, M. D. S. Etnoconservação e consumo nas várzeas dos rios Solimões e Amazonas. In: MING, L. C.; AMOROZO, M. C. de M.; KFFURI, C. W. (Org.). Agrobiodiversidade no Brasil: experiências e caminhos da pesquisa. Recife: NUPEA, 2010. (Série Estudos \& Avanços, v. 6).

OLLAGNON, H. Estratégia patrimonial para a gestão dos recursos e dos meios naturais: enfoque integrado da gestão do meio rural. In: VIEIRA, Paulo Freire; WEBER, J. (Org.). 
Gestão de recursos naturais renováveis e desenvolvimento: novos desafios para a pesquisa ambiental. São Paulo: Cortez, 1997. p. 171-200.

POSEY, D. Etnobiologia: teoria e prática In: RIBEIRO, Darcy (Ed.). Suma etnológica brasileira. Petrópolis, RJ: Vozes/FINEP, 1987. p. 15-28.

SANTILLI, J. F. da R. Agrobiodiversidade e direitos dos agricultores. São Paulo: Peirópolis, 2009. 410p.

SANTOS, M. A natureza do espaço. Técnica e tempo. Razão e emoção. 4. ed. São Paulo: EDUSP, 2006.

SEVERINO, A. J. Metodologia do trabalho científico. 23. ed. São Paulo: Cortez, 2007. 304p.

SILVANO, R. A. M.; SILVA, A. L.; CERONE, M.; BEGOSSI, A. Contributions of Ethnobiology to the conservation of tropical rivers and streams. Aquatic Conservation, Marine and Freshwater Ecosystems, v. 18, n. 3, p. 241-60, maio 2008.

SILVANO, R. A. M.; BEGOSSI, A. Local knowledge on a cosmopolitan fish, ethnoecology of Pomatomus saltatrix (Pomatomidae) in Brazil and Australia. Fisheries Research, v. 71, n. 1, p. 43-59, jan. 2005.

TOLEDO, V. M. La memoria tradicional: la importancia agroecológica de los saberes locales. LEISA, Revista de Agroecología, Lima, Peru, v. 20, n. 4. p. 16-9, abr. 2005.

TUAN, Y. Espaço e lugar: a perspectiva da experiência. Tradução Lívia de Oliveira. Londrina, PR: EDUEL, 2013. 248p.

VIEIRA, J. M. T. A luta pelo reconhecimento étnico dos Kokama na Tríplice Fronteira Brasil/ Colômbia/Peru. 2016. Tese (Doutorado em Antropologia Social)- Instituto de Filosofia e Ciências Humanas, Universidade Estadual de Campinas (UNICAMP), Campinas, SP, 2016.

YIN, R. K. Estudo de caso: planejamento e métodos. 5. ed. Porto Alegre: Bookman, 2015. 290p.

\section{Sobre os autores:}

Antonia Ivanilce Castro Dácio: Doutorado e Mestrado em Ciências do Ambiente e Sustentabilidade na Amazônia, graduação em Agronomia pela Universidade Federal do Amazonas. Pesquisadora do Núcleo de Estudos Rurais e Urbanos Amazônico (NERUA/INPA) e do Núcleo de Etnoecologia na Amazônia Brasileira (NETNO/UFAM). Professora da Universidade Federal do Amazonas/Instituto de Natureza e Cultura. Tem experiência na área de Agronomia, com ênfase em Agricultura Familiar, atuando principalmente nos seguintes temas: segurança ali- 
mentar, abastecimento local, agroecologia, etnoconservação e recursos genéticos vegetais. E-mail: ivanilcecastro@ufam.edu.br

Hiroshi Noda: Doutorado e Mestrado em Genética e Melhoramento de Plantas e Graduação em Engenharia Agronômica pela Escola Superior de Agricultura Luiz de Queiroz da USP. Graduação em Licenciatura em Filosofia pela Universidade Católica de Santos. Pesquisador Titular Aposentado do Instituto Nacional de Pesquisas da Amazônia (INPA), pesquisador dos grupos de pesquisa do Núcleo de Estudos Rurais e Urbanos Amazônicos (NERUA) da Coordenação Sociedade, Ambiente e Saúde do INPA e do Núcleo de Etnoecologia na Amazônia Brasileira (NETNO) da Faculdade de Ciências Agrárias da Universidade Federal do Amazonas (UFAM). Docente do quadro permanente do Curso de Pós-graduação em Ciências do Ambiente e Sustentabilidade na Amazônia do Centro de Ciências do Ambiente da UFAM. Tem experiência na área de agronomia, com ênfase em melhoramento genético de hortaliças para cultivo no Trópico Úmido, conservação e melhoramento; recursos genéticos vegetais nativos da Amazônia, agricultura familiar e tradicional, segurança alimentar no meio rural. E-mail: hnoda@inpa.gov.br

\section{Recebido em 2 de abril de 2018}

Aprovado para publicação em 24 de julho de 2018 
